\title{
Postpartum Recovery
}

National Cancer Institute

\section{Source}

National Cancer Institute. Postpartum Recovery. NCI Thesaurus. Code C92936.

The healing and recuperation of the mother including physiological readjustment after pregnancy and delivery of the baby. 